\title{
Perceptions and Linguistic Actions of Bilingual Speakers of Turkish and English: An Explanatory Study
}

\author{
Esim Gursoy ${ }^{1}$, Eda Nur Ozcan ${ }^{2 *}$ \\ ${ }^{1}$ Fculty of Education, ELT Department Uludag University, Bursa, Gorukle, Turkey \\ ${ }^{2}$ The Institute of Educational Sciences, Uludag University, Bursa, Gorukle, Turkey
}

Corresponding Author: Eda Nur Ozcan, E-mail: ozcanedanur@outlook.com

\begin{tabular}{l} 
ARTICLE INFO \\
\hline Article history \\
Received: August 14, 2018 \\
Accepted: October 29, 2018 \\
Published: December 28, 2018 \\
Volume: 9 Issue: 6 \\
Advance access: November 2018 \\
\hline Conflicts of interest: None \\
Funding: None
\end{tabular}

Key words:

Bilingualism,

Early Bilinguals,

Late Bilinguals,

Biculturalism,

Language Choice,

Linguistic Actions

\begin{abstract}
Due to the globalized world, sixty percent of world's population is bilingual today. Such a population calls for the need to understand bilinguals from a holistic perspective since it is likely that we are surrounded by bilinguals and we are raising bilingual children. Therefore, this study investigates bilingualism from five different dimensions; their perception of bilingualism and languages as Turkish and English, prosodic features in these two languages, sense of self, biculturalism and their language choice to get an overview about bilingual speakers of Turkish and English by adopting a qualitative design. Moreover, this study is one of the few studies involving bilinguals of Turkish and English. The data was collected from 29 bilinguals through an open-ended questionnaire. In data analysis, participants were divided into two main groups as early and late bilinguals; the origins of the bilinguals were also taken into account. Bilinguals' responses were examined by using inductive data analysis. The results show that bilingual speakers have a unique profile and they make their decisions depending on the context, culture, self-perception and sense of self. Each bilingual is found to be idiosyncratic with linguistic and non-linguistic behaviour he/she displays.
\end{abstract}

\section{INTRODUCTION}

There has been a surge of interest in bilingualism for almost a century. Especially in the last three decades, the numbers of studies have increased in the field as a result of globalization. Recently, more than half of the world has been estimated to be bilinguals due to the reason that the borders are fading away. Providing a definition of bilingualism for this research seems necessary since the definitions vary as to age, context, order of acquisition and language proficiency of speakers. Grosjean (1994) defines that bilinguals are those who actively use two languages in their daily life. Bilingualism is seen as a merit today as these individuals can open the gateway between two different contexts. It has been claimed that bilinguals' experience of life is different than that of monolinguals. Eva Hoffman's (1989) novel, Lost in Translation, is of prime importance while discussing the issue. The Polish writer immigrated with her family to Canada and in her novel; she talks about her experience in-between two languages. Tzvetan Todorav is another writer who experienced the same when he emigrated from Bulgaria to France. Feeling of duality was reported by the two writers; however, this duality was not per- ceived as an advantage once. Adler (1977) named this experience as split personality and warned people that the split could cause schizophrenia. Later, many researchers investigated the cognition of bilinguals to see whether this experience was harmful. It was found that bilingual individuals have advantages over monolinguals, for instance, even hearing two languages at the same time at early ages is good for cognitive development (Bialystok, Craik \& Ryan, 2006). Yet still, very limited number of research has focused on the holistic nature of bilinguals and very few of them have targeted bilingual speakers of Turkish and English. Therefore, we aim to investigate this population to get an in-depth understanding of their perceptions of bilingualism and linguistic actions. With this aim, we set specific goals to investigate (a) a multifaceted understanding of bilingualism from 5 different dimensions, (b) to discover how the nature of early bilinguals (EB) and late bilinguals (LB) differ in terms of their perceptions and (c) to see if bilinguals are two monolinguals in one body or they have a unique profile (Grosjean, 1982). To be able to answer our questions and to attempt to understand bilinguals of Turkish and English from different perspectives lead us to adopt a qualitative approach. 


\section{LITERATURE REVIEW}

There is almost no study in the literature, looking bilingualism from different perspectives at once. Most researchers focused on one or two dimensions about bilingual speakers. Taking Pavlenko (2007) as an example, she investigated emotions of bilinguals in different languages and found out that some bilinguals saw the world different than others. They changed their perspectives, linguistic and non-linguistic behaviours with language and this dynamism gave some bilinguals excitement while others showed disfavour. She also maintained that bilinguals felt artificial and fake because of their low language proficiency. Some researchers investigated whether or not bilinguals felt and acted different when they switched languages (Dewaele, 2015; Koven, 2007; Wilson, 2013). Feeling different means they do not entirely feel like themselves. Acting and feeling different were found to be linked to many different variables. According to Wilson (2013), feeling different resulted from lack of proficiency. Educational level of bilinguals played an important role in feeling different (Dewaele, 2015). Older bilinguals were found to feel the difference more (Dewaele \& Li Wei, 2014) and anxiety also contributed to feeling different (Dewaele, 2015). Some researchers put forward that feeling different occurred in accordance with personality traits of bilinguals (Ozanska-Ponikwia, 2012, 2013; Wilson, 2008, 2013). It was also shown that there was a close relationship between personality traits and acculturation, being less emotionally stable and socially initiative contributes to feeling different with different languages (Panicacci \& Dewaele, 2017). When it comes to biculturalism, relevant literature stated that being bicultural can either be an advantage or a disadvantage for people. According to Benet-Martinez, Lee $\&$ Leu (2006), biculturals are creative, flexible and have high degree of integration with the assistance of two different cultures. On the other hand, according to Rudmin (2003), biculturalism can cause identity confusion. Being a bicultural takes the adjustment strategies, that is to say, biculturals adapt to the environment by employing different methods. The researchers working on the adjustment strategies showed that both psychological and sociocultural strategies are used during the process (Berry, Phinney, Sam \& Vedder, 2006). Both strategies were proved to be equally significant for adjustment (Benet-Martinez \& Nguyen, 2013). For language choice, bilinguals seemed to depend on the context in which the function of language is mostly used. Previous research studies demonstrated that the language of mental calculation is the language in which bilinguals got instructed (Bialystok, 2005), while there can still be other factors in language choice, for instance, language proficiency can affect bilinguals' language choice seeing that intermediate learners tend to use L2 more (Centeno-Cortes \& Jimenez Jimenez, 2004; Cohen, 1994). The language of inner speech has been found to be linked with the context shaped by bilinguals' autobiographic memory. (Larsen, Schrauf, Fromholt and Rubin, 2002; Schrauf \& Rubin, 2000). Lastly, non-linguistic signals were found to change from culture to culture (Oguibe, 1992; Zhi-pen, 2004). Nonetheless, when the previous studies are taken into consideration about bilingual speakers, Pavlenko
(2007) claims that "a uniform answer is neither possible nor desirable. (p.6)"

As the literature has suggested, bilingualism is a fluid construct depending on many variables such as languages, cultures, context, age, proficiency, and so forth. Thus, coming up with assumptions and expecting them to be consistent with the previous findings would be inappropriate in this case. On the basis of these concerns, this research aims to reveal the holistic nature of bilinguals by focusing on a certain population. Since the sampling of the present research is different from what is existent in the relevant literature, obtaining different results are likely to come out.

\section{METHOD}

\section{Research Design}

In order to get a comprehensive understanding of bilinguals of Turkish and English and to investigate how the nature of early bilinguals (EB) and late bilinguals (LB) differs in terms of their perceptions, qualitative research design has been adopted.

\section{Participants}

We used a non-probability sampling technique to reach the participants. 29 bilingual speakers of Turkish and English (22 females and 7 males) participated in the present study. The majority of participants were reached through a Facebook group and all were voluntary, whereas, some were reached via snowball sampling technique. The average age of participants is 43 , ranging from 22 to $59(\mathrm{SD}=9) .27$ participants are Turkish, 2 participants are British. The linguistic information of participants presents that the study involves 16 bilinguals, 6 trilinguals and 7 quadrilinguals. 24 participants were born in Turkey, 3 in UK, 1 in Sweden and 1 in the US. Participants were named as either early or late bilinguals, based on a former study (Hull \& Vaid, 2007), If they learn their L2 (Turkish or English) after 5 years old, they are regarded as late bilinguals. The study involves 7 early and 22 late bilinguals of Turkish and English. 22 participants currently reside in England, 3 in the USA and 5 in Turkey. It is important to note that 2 participants residing in Turkey include the British participants and they are late bilinguals, they helped us to constitute another perspective in this study as their data was separately analysed. The average number of years spent in English-speaking and Turkish-speaking country is respectively 20.72 and 20.76 years. The education level of participants varies as high-school diplomas $(n=2)$, undergraduate degrees $(n=16)$, postgraduate degrees $(n=9)$ and doctoral degrees $(n=2)$. 22 Turkish participants stated that they use English more, while 7 participants use Turkish more. British participants stated that they use Turkish more in their daily life. 6 early bilinguals stated that their dominant language is English, while only 4 of late bilinguals mention English as the dominant language. The only early bilingual who stated his dominant language as Turkish was exceptional in that he was raised by a Turkish mother and an American father in Turkey. As it is expected, British participants stated that their dominant language is English. 


\section{Instrumentation}

Open-ended questions addressing five different dimensions were prepared after the relevant literature had been scanned. To measure the content validity of the instrument, some of the questions were revisited with the help of six experts and some questions were eliminated as the result of Lawshe's content validity ratio (1975). To apply the technique, experts were sent the questionnaire online and asked to make decisions about each item by offering three options; essential, useful but not essential and not necessary as the technique itself suggests. Obtained results helped us to form the content of the questionnaire. To measure the face validity, the final version of the instrument was proofread by a native speaker of English. The questionnaire included three sections; demographic information, linguistic information and the field questions aiming to unearth five dimensions lying behind bilingualism. The instrument was a web-based questionnaire prepared through Google Forms. Questions regarding language choice and linguistic information were adopted from Bilingualism and Emotion Questionnaire (BEQ) (Dewaele \& Pavlenko, 2001/2003). After the instrument was set in terms of validity, the instrument was translated into Turkish and it was checked through back-translation technique by three different assessors. The final version of instrument included 13 open-ended field questions and came out with two different language options.

A need for structured-interview existed during the data analysis and 9 participants who stated physical difference when the language is switched were asked for interview to be able to reach a deeper insight into the matter under the question, only one participant responded to the interview request.

\section{Data Collection Procedure}

Participants were asked if they were voluntary or not on Facebook. The instruments with two language options were sent to them when they stated that they wanted to participate in the study. They were given a brief explanation about the purpose and asked to click on the questionnaire link in whichever language they wanted to fill in. There was no time restriction; participants could complete the questionnaire anytime they wished during two weeks. Some of the participants had to be excluded from data analysis since some left the instrument incomplete or they did not meet the requirements of the study. For example, those who spent less than 10 years in English-speaking countries were excluded.

\section{Data Analysis}

We began data analysis with already existed themes in questionnaire; however, the raw data helped us to come up with codes, then categories through the use of both inductive and deductive analysis. Inductive analysis enabled us to come up with new assumptions while deductive analysis helped us to check if the data showed consistency with previous assumptions. While the questions were analysed, the responses were divided into two groups as the responses of early bi- linguals and late bilinguals. The response of participants to each question was read horizontally several times. Responses were underlined and coloured, depending on frequency, differences and similarities. Coloured and underlined raw data were coded. During the coding process, responses were revisited several times to make sure that codes are reflectors of responses and consistent with the whole data. As Thomas (2006) has suggested while discussing coding process of inductive approach, the code labels were created from the actual words or phrases that participants used in their answers. Categories were created as the result of emerging codes and a reliability check was administered on categories with the help of a colleague. Finally, emerging codes and categories were re-read until we settled down on the final units.

\section{RESULTS AND DISCUSSION}

Thirteen open-ended questions approaching the issue of bilingualism from five different dimensions and linguistic information shared by the participants allowed us to shape our ideas about participants as thirteen different answers enabled us to gain insight into each participant. Dealing with qualitative data on five different dimensions leads us to discuss results one by one. Before sharing the findings, it is important to note that some participants did not provide an answer to some questions or they provided irrelevant answers, thus such responses could not be examined.

\section{Bilingual Perception of Bilingualism and Languages}

Participants were asked whether they would call themselves a bilingual, only one participant (P7-LB) answered this question negatively even though she has been currently living in the UK for fifteen years and the same participant answered other questions in a similar way.

"I easily adapt to my environment but I hardly give up my habits." [Yaşadığım yere kolay uyum sağlarım ama alışkanlıklarımdan da pek vazgeçmem.]

"English is makeshift." [İngilizce eğreti.]

The second question was asked to reveal participants' feelings about being able to use two languages. The responses concerning why bilinguals feel in those ways are codified in Table 1. The majority of the participants stated that they feel lucky about using two languages. One participant (P7) stated feeling neutral. P12 (LB) answering as neutral may share common feelings with P7, as P12 wrote "English is cold." in the questionnaire. The rest of the participants feeling neutral have been found multilingual as a distinct feature when compared with other participants.

Participants' feelings were asked when they use each language. The findings analysed from the raw data concerning bilinguals' feelings towards each language are shown in Table 2 and Table 3. It is seen that feelings towards using Turkish gathered around language use.

Participants were asked about their feeling while they were using English. Different from what has been found about feelings regarding Turkish use, feelings regarding English use are seen to be blending with language proficiency as it is exemplified in Table 3 below. 
As the last question of this dimension, participants were asked to describe two languages with an adjective. As a result of data analysis, the responses were categorized under three different codes.

While bilingual participants were found to define the Turkish language with language related descriptions, the English language was defined with feeling related descriptions more. The examples can be found in the Table 5 below.

When Table 4 and 5 are compared, English is described with feeling-based adjectives more. While Turkish is ap- proached more objectively, descriptions of the English language include subjectivity more. When the responses of EBs, LBs and BPs were examined separately, none of the participant groups seemed to be following a fixed orientation; rather responses seemed to be idiosyncratic.

\section{Bilingual Perception of Non-linguistic Features}

The participants were asked whether they feel physical difference when they switch between languages, 9 participants

Table 1. The emerging codes regarding the sources of participants' feelings

\begin{tabular}{|c|c|c|c|}
\hline & Category/Frequency & Code & Example Meaning Unit \\
\hline \multirow[t]{2}{*}{$\begin{array}{l}\text { The sources of the } \\
\text { feelings of bilinguals }\end{array}$} & Feeling lucky $(n=24)$ & $\begin{array}{l}\text { Communicating with the world } \\
\text { Being familiar to other cultures } \\
\text { Opportunity at work } \\
\text { Opportunity to reach more information }\end{array}$ & $\begin{array}{l}\text { "Lucky because I can communicate with } \\
\text { people around the world (P13-LB)." } \\
\text { "Lucky, an opportunity to get to know } \\
\text { both cultures (P4-LB)." } \\
\text { "Lucky, it gives me more opportunities } \\
\text { within work environment. Translation } \\
\text { skills have improved (P21-EB)." } \\
\text { "Lucky. I can communicate with people } \\
\text { from different societies. I can reach } \\
\text { more written materials (P20-LB)." }\end{array}$ \\
\hline & Feeling neutral $(n=5)$ & The nature of language learning & $\begin{array}{l}\text { "Neutral. We are born to } \\
\text { learn (P12-LB)." } \\
\text { "It comes naturally (P8-LB)." }\end{array}$ \\
\hline
\end{tabular}

Table 2. The emerging codes regarding participants' feelings towards Turkish

\begin{tabular}{llll}
\hline & Category/Frequency & Code & Example Meaning Unit \\
\hline $\begin{array}{l}\text { Feelings towards } \\
\text { using Turkish }\end{array}$ & $\begin{array}{l}\text { Feelings related to language } \\
\text { use }(n=15)\end{array}$ & $\begin{array}{l}\text { Natural } \\
\text { Emotional }\end{array}$ & $\begin{array}{l}\text { "Natural. It's a gift to speak (P21-EB)." } \\
\text { "Turkish: Emotional/longing (P10-LB)." }\end{array}$ \\
& $\begin{array}{l}\text { Feelings related to language } \\
\text { proficiency }(n=13)\end{array}$ & $\begin{array}{l}\text { Comfortable } \\
\text { "I feel comfortable speaking Turkish most of the time (P25-EB)." }\end{array}$ & \begin{tabular}{l} 
"I feel completely content and efficient (P26-EB)." \\
\hline
\end{tabular}
\end{tabular}

Table 3. The emerging codes regarding participants 'feelings towards English

\begin{tabular}{|c|c|c|c|}
\hline & Category/Frequency & Code & Example Meaning Unit \\
\hline \multirow[t]{2}{*}{$\begin{array}{l}\text { Feelings towards using } \\
\text { English }\end{array}$} & $\begin{array}{l}\text { Feelings related to language } \\
\text { proficiency }(n=15)\end{array}$ & $\begin{array}{l}\text { Comfortable } \\
\text { Uncomfortable }\end{array}$ & $\begin{array}{l}\text { "Very comfortable with English (P11-LB)." } \\
\text { "I feel that I cannot totally master English (P20-LB)." }\end{array}$ \\
\hline & $\begin{array}{l}\text { Feelings related to language } \\
\text { use }(n=11)\end{array}$ & $\begin{array}{l}\text { Natural } \\
\text { Confident } \\
\text { Unnatural }\end{array}$ & $\begin{array}{l}\text { "Natural (P15-P1-LBs)." } \\
\text { "Speaking more than one language natively is } \\
\text { powerful (P22-EB)." } \\
\text { "I feel confident (P25-EB)." } \\
\text { "English: Somehow artificial (P14-LB)." }\end{array}$ \\
\hline
\end{tabular}

Table 4. The emerging codes regarding bilinguals' descriptions of Turkish

\begin{tabular}{|c|c|c|c|}
\hline & Category/Frequency & Code & Example Meaning Unit \\
\hline \multirow[t]{3}{*}{$\begin{array}{l}\text { Description of Turkish in } \\
\text { the eye of bilinguals }\end{array}$} & $\begin{array}{l}\text { Language related } \\
\text { descriptions }(n=16)\end{array}$ & $\begin{array}{l}\text { Rich } \\
\text { Complex }\end{array}$ & $\begin{array}{l}\text { "Artsy (P26-EB)." } \\
\text { "Turkish is "jaunty" with all the dots in the written language } \\
\text { and the rhythm of the syllable-timed language (P28-LB)." } \\
\text { "Elaborated (P18-EB)." } \\
\text { "Mathematical (P14-LB)." }\end{array}$ \\
\hline & $\begin{array}{l}\text { Feeling related } \\
\text { descriptions }(n=9)\end{array}$ & Emotional & $\begin{array}{l}\text { "Turkish language is emotional deep feelings and } \\
\text { poetic (P21-EB)." }\end{array}$ \\
\hline & $\begin{array}{l}\text { Function related } \\
\text { descriptions }(n=3)\end{array}$ & Expressive & "Expressive (P22-EB, P19-LB)." \\
\hline
\end{tabular}


responded affirmatively while the rest mentioned no physical difference. Table 6 reveals in which ways participants feel the physical differences.

A similar question was asked for revealing hypothetical speech differences. 14 participants responded affirmatively. Table 7 presents how this difference occurs.

The frequency of responses has shown that body movements were more associated with Turkish, while face gestures were associated with English. No direct conclusion can be drawn amongst EBs, LBs and BPs as some responded affirmatively and some did not. For the elaboration of the associations of body language with English and Turkish, P22 (EB) was interviewed on what reasons might trigger the use of facial gestures with English.

"I would say that facial gestures are more in English. Hand gestures are more in Turkish. I think both result from the culture. English people hold themselves back,
They do not tell things bustlingly much, so I think they express themselves by using facial expression."

For speech difference, it has been revealed that the speed of speech is not an issue concerning the nature of language; it is about experience concerning language use since EBs reported they speak faster when they speak English, while LBs stated vice versa. Also, EBs reported that they do not feel any change in their tone of voice while LBs reported a change in their tone of voice, including one BP.

\section{Bilingual Perception of "Sense of Self"}

The questions addressing the feeling of participants' personality change received 9 affirmative answers. The majority of the participants did not state any change. The ways participants felt difference/change are presented in Table 8 .

Table 5. The emerging codes regarding bilinguals' descriptions of English

\begin{tabular}{llll}
\hline & Category/Frequency & Code & Example Meaning Unit \\
\hline $\begin{array}{l}\text { Description of English } \\
\text { in the eye of bilinguals }\end{array}$ & Feeling related descriptions $(n=12)$ & Useful Cold & "Practical (P20-LB)." \\
& & & "Though English is very rich and beneficial, I find \\
& & & $\begin{array}{l}\text { it cold due to foreignness (P18-LB)" } \\
\text { Language related descriptions }(n=10)\end{array}$ \\
& Function related descriptions $(n=4)$ & Rich & "Flexible (P29-LB)." \\
& & & "English is more straightforward (P21-LB)." \\
\hline
\end{tabular}

Table 6. The emerging data regarding the areas physical differences occur

\begin{tabular}{llll}
\hline & Category/Frequency & Code & Example Meaning Unit \\
\hline $\begin{array}{l}\text { The areas physical } \\
\text { differences occur }\end{array}$ & Visual prosody $(n=9)$ & Body Movements & $\begin{array}{l}\text { "Yes. My gestures change. I think it is not only because of the } \\
\text { language but also the culture and person you are interacting. } \\
\text { Turkish is more lively. (P4-LB)." } \\
\end{array}$ \\
& & Facial Gestures & $\begin{array}{l}\text { "I use more gestures and facial expressions when speaking } \\
\text { English (P25-EB)." }\end{array}$ \\
\hline
\end{tabular}

Table 7. The emerging data regarding the areas vocal difference occurs

\begin{tabular}{|c|c|c|c|}
\hline & Category/Frequency & Code & Example Meaning Unit \\
\hline \multirow[t]{2}{*}{$\begin{array}{l}\text { The areas vocal } \\
\text { difference occurs }\end{array}$} & Vocal prosody $(n=14)$ & Tone of voice & $\begin{array}{l}\text { "Yes. Intonation changes depending on the person I am speaking to } \\
\text { and the content of the conversation (P17-LB)." }\end{array}$ \\
\hline & & Speed & $\begin{array}{l}\text { "Yes, I think while I am speaking English, I speak more slowly, so } \\
\text { as to be sure... (P10-LB)." } \\
\text { "Sometimes. English I speak very fast while Turkish I speak } \\
\text { slower (P21-24-EBs)." }\end{array}$ \\
\hline
\end{tabular}

Table 8. The emerging codes regarding participants' personality change

\begin{tabular}{|c|c|c|c|}
\hline & Category/Frequency & Code & Example Meaning Unit \\
\hline \multirow[t]{5}{*}{$\begin{array}{l}\text { Feeling personality change } \\
\text { when speaking English }\end{array}$} & Change within self $(n=7)$ & Safe & $\begin{array}{l}\text { "I feel safer and freer while I am speaking } \\
\text { English (P10-LB)." }\end{array}$ \\
\hline & & Calm & $\begin{array}{l}\text { "Yes, I am calmer and more careful in } \\
\text { English (P4-LB)." }\end{array}$ \\
\hline & & Social & $\begin{array}{l}\text { "Yes I am more outgoing when I speak } \\
\text { English (P2-LB)." }\end{array}$ \\
\hline & & Confident & $\begin{array}{l}\text { "Yes I feel I have a higher level of self-confidence } \\
\text { when I'm speaking English (P26-EB)." }\end{array}$ \\
\hline & Change towards society $(n=2)$ & Kind & $\begin{array}{l}\text { "I become more respectful and kinder while } \\
\text { speaking English (A habit from England, It did } \\
\text { not happen in USA (P24-EB)." }\end{array}$ \\
\hline
\end{tabular}


No fixed orientation has been observed in the responses of LBs and EBs since both groups responded in two different ways. Although the table only represents the change in use of English, one BP stated that she felt difference in her personality.

"Yes, I am noisier and more assertive in Turkish. (P28-LB)"

This response can also be categorized under our emerging codes. Thus, the codes are not language-specific.

\section{Bilingual Perception of Biculturalism}

Participants were asked whether they would call themselves a bicultural. Only six participants responded the question negatively, from these participants we elicited very sharp responses.

"No, because there is nothing noteworthy in American culture so I prefer preserving my own culture (P17-LB)" "No, I say I am in the Turkish culture. I have not adjusted to English culture. Parents brought us up knowing our values and respect to Turkish culture (P21-EB)."

"No, I never feel that I belong to the Turkish culture (P10-LB)."

It has been seen that the perception of biculturalism is not related to early or late bilingualism as two of negative responses came from EBs. BPs stated that they felt bicultural;
"Yes, I have absorbed Turkish culture (P29-LB)."

"Yes. Although I wouldn't say being British or Turkish are two ends of a continuum. I was born and brought up in the north of England in the 1970s-1980s, so a lot of my "core" characteristics have been shaped by that context. However, living in Turkey for 22 years has also added elements of Turkishness to my identity (P28-LB)."

Participants' explanations about the reason why they perceive themselves as bicultural are tabulated in Table 9. The emerging codes are consistent with BPs' explanations, too. We used priori categories for cultural adjustment and came up with two emerging codes under each of them.

In the following question, participants were asked which culture they found to be representative of themselves and what causes it. 12 participants responded as the Turkish culture and 7 participants came up with a reason. The responses are codified under one category in Table 10.

8 participants responded as the British culture and 7 participants came up with the reasons. 2 of 8 participants include BPs as one would expect. The responses are codified under two priori categories. One category was the same as the one in Table 10 but the codes differ (Table 11).

The rest of the participants who did not offer a reason stated that they are representatives of both cultures at the same time.

Table 9. The emerging codes regarding participants' perceptions of biculturalism

\begin{tabular}{|c|c|c|c|}
\hline & Category/Frequency & Code & Example Meaning Unit \\
\hline \multirow{4}{*}{$\begin{array}{l}\text { Reasons for the } \\
\text { perception of } \\
\text { biculturalism }\end{array}$} & \multirow[t]{2}{*}{ Psychological adjustment $(n=16)$} & Experience & $\begin{array}{l}\text { "Yes I would I have lived longer in the UK than } \\
\text { Turkey (P19-LB)." }\end{array}$ \\
\hline & & Survival & $\begin{array}{l}\text { "Yes because you need to keep up with the culture you are } \\
\text { living in (P15-LB)." }\end{array}$ \\
\hline & \multirow[t]{2}{*}{ Sociocultural adjustment $(n=4)$} & Traditions & $\begin{array}{l}\text { "Celebrating Eid. Living in the UK in some way or another you } \\
\text { have to join in their tradition as well. Eg. Children giving school } \\
\text { friends Christmas cards (P23-EB)." }\end{array}$ \\
\hline & & Marriage & $\begin{array}{l}\text { "My English husband, I have children who grew up in two } \\
\text { different countries (England and Switzerland) with English, } \\
\text { German, Turkish, French and Macedonian. I belong to the } \\
\text { world (P17-LB)." }\end{array}$ \\
\hline
\end{tabular}

Table 10. The emerging codes concerning the reasons of adoption of the Turkish culture

\begin{tabular}{llll}
\hline & Category/Frequency & Code & Example Meaning Unit \\
\hline $\begin{array}{l}\text { The reasons why bilinguals find the } \\
\begin{array}{l}\text { Turkish culture more representative of } \\
\text { themselves }\end{array}\end{array}$ & $\begin{array}{l}\text { Psychological } \\
\text { adjustment }(n=7)\end{array}$ & Origin-based & $\begin{array}{l}\text { "Because it defines me, my family and my } \\
\text { ancestors (P25-EB)." } \\
\text { "It is our origin (P15-LB)." } \\
\text { "It sounds more close to me, I feel more } \\
\text { natural (P5-LB)." }\end{array}$ \\
\hline
\end{tabular}

Table 11. The emerging codes concerning the reasons of adoption of the British culture

\begin{tabular}{llll}
\hline & Category/Frequency & Code & Example Meaning Unit \\
\hline $\begin{array}{l}\text { The reasons why Bilinguals find the } \\
\text { British culture more representative of } \\
\text { themselves }\end{array}$ & $\begin{array}{l}\text { Psychological } \\
\text { adjustment }(n=4)\end{array}$ & Experience & "Host Culture, because I feel more accustomed to \\
& $\begin{array}{l}\text { Sociocultural } \\
\text { adjustment }(n=3)\end{array}$ & $\begin{array}{l}\text { Ethics } \\
\text { Practices }\end{array}$ & $\begin{array}{l}\text { "P26-EB)." } \\
\text { "People are given more importance (P7-LB)." } \\
\text { Britain (P22-EB)." go about doing things in }\end{array}$ \\
\hline
\end{tabular}


"Both, especially after a long time, Turkish people say that I am like an English person, English people say that I still keep Turkish culture (P4-LB)."

When the responses of LBs and EBs were compared, the responses appeared to be quite personal. The emerging codes are worthy of attention for the representativeness of British culture since we came up with experience-specific reasons, differing from Table 10. When it comes to BPs, one stated an origin-based reason while the other gave no explanation for the representativeness of the British culture.

As the last question of this dimension, participants were asked whether they felt the need to change themselves as to the cultural setting. 9 participants responded affirmatively and 7 brought explanation. The explanations are tabulated in Table 12 below.

When the responses of EBs and LBs are compared, only one EB stated affirmatively. His response can be categorized under the codes.

"Immediately after I leave the plane, I turn back to my Turkishness, It is hard to live in Turkey as an English man (P24-EB)."

One of the BPs (P28) responded affirmatively to this question while the other participant responded "No."

\section{Language Choice of Bilinguals}

Three questions were addressed to the bilingual speakers to reveal their language choices at a personal level. As we have mentioned in the instrument part, the questionnaire had language options as Turkish and English. The questionnaire played a role in the findings of language choices, as well.
Participants were asked which language they prefer when they are making their inner speech. Of all the participants answering this question stated that 9 participants use English, 3 participants use Turkish and the rest responded that they use both depending on the context. Those using Turkish include only LBs. 8 LBs used English while the rest used both languages. Out of 7 EBs, 5 stated using both of them, 2 stated using English. When BPs were taken into analysis, one stated using English, one stated using both.

When participants were asked which languages they use for mental calculation, 14 participants stated using Turkish, 12 participants stated using English and 3 participants stated using both. 5 EBs stated using English, 1 stated using Turkish and 1 stated using both. 6 LBs stated using English and only 2 stated both. BPs stated using English.

When it comes to the questionnaire, 16 participants filled it in English while 13 participants preferred Turkish. Only 2 EBs preferred Turkish. BPs filled it in English.

Participants were also asked in which language they would write a diary, 15 participants preferred English, 9 preferred Turkish and 5 responded as "both". 4 EBs preferred English, 2 preferred Turkish and 1 stated as "both". BPs preferred English. When participants were asked about the reason why they use that language, the reasons have been found to be person-specific. Table 13 tabularises coded reasons of users' preference of keeping their diary in Turkish.

Table 14 below tabularises coded reasons of users' preference of keeping their diary in English.

BPs mentioned about the practicality of English for themselves. LBs and EBs have been observed to choose the language depending on their own rationale.

Table 12. The emerging codes concerning the reasons why bilinguals are shaped as to the cultural setting

\begin{tabular}{llll}
\hline & Category/Frequency & Code & Example Meaning Unit \\
\hline $\begin{array}{l}\text { The reasons why bilinguals } \\
\text { changed themselves as to the } \\
\text { cultural setting }\end{array}$ & $\begin{array}{l}\text { Sociocultural } \\
\text { adjustment }(n=9)\end{array}$ & $\begin{array}{l}\text { Avoiding } \\
\text { misunderstanding }\end{array}$ & $\begin{array}{l}\text { "In Turkey, Smile less, be concise otherwise } \\
\text { you will get misunderstood or taken the wrong } \\
\text { way (P9-LB)." } \\
\text { "In the UK I feel I can greet people, say "Hello" or } \\
\text { even share a joke even if I don't know them, in a } \\
\text { shop, waiting for a bus, in a lift etc., In Turkey, I try } \\
\text { to avoid eye contact outside (P28-LB)." } \\
\text { "I mind etiquette in every country (P17-LB)." } \\
\text { "For example, I do not drive a car in Turkey. If you } \\
\text { follow the traffic rules, you cannot drive a car in } \\
\text { Turkey. (P7-LB)." }\end{array}$ \\
\hline
\end{tabular}

Table 13. The emerging codes concerning participants' choice of Turkish in writing a diary

\begin{tabular}{llll}
\hline & Category/Frequency & Code & Example Meaning Unit \\
\hline $\begin{array}{l}\text { The reasons why bilingual } \\
\text { participants use Turkish in diary } \\
\text { writing }\end{array}$ & Personal reasons $(n=6)$ & $\begin{array}{l}\text { Experience with the } \\
\text { language Privacy }\end{array}$ & $\begin{array}{l}\text { "The language that I can express myself } \\
\text { better is Turkish (P6-LB)" } \\
\text { "If you are in another country, you can } \\
\text { leave your diary anywhere, even if they } \\
\text { read it, they will not understand (P10-LB)." } \\
\text { Linguistic reasons }(n=1)\end{array}$ \\
& Practicality & $\begin{array}{l}\text { "I feel more comfortable and know how } \\
\text { to spell difficult words. While in English } \\
\text { difficult words have hidden letters; I feel } \\
\text { confused (P21-EB)." }\end{array}$ \\
\hline
\end{tabular}


Table 14. The emerging codes concerning participants' choice of English in writing a diary

\begin{tabular}{llll}
\hline & Category/Frequency & Code & Example Meaning Unit \\
\hline $\begin{array}{l}\text { The reasons why bilingual } \\
\text { participants use English in } \\
\text { diary writing }\end{array}$ & $\begin{array}{l}\text { Linguistic reasons }(\mathrm{n}=9) \\
\text { Personal reasons }(\mathrm{n}=3)\end{array}$ & $\begin{array}{l}\text { Practicality } \\
\text { Experience with } \\
\text { the language } \\
\text { Privacy }\end{array}$ & $\begin{array}{l}\text { "In English (only because Turkish takes too } \\
\text { long (P13-LB)." } \\
\text { "English because I'm more used to that } \\
\text { alphabet (S26)." } \\
\text { "People who do not know English wouldn't be able } \\
\text { to understand (P25-EB)" }\end{array}$ \\
\hline
\end{tabular}

\section{DISCUSSION}

\section{Bilingual Perception of Bilingualism and Languages}

Understanding bilinguals is rather complex but it is intriguing at the same time. Before starting the discussion, we feel the need to clarify a common misconception concerning this issue. When bilingualism is mentioned, many people assume that being a bilingual means having the equal command of both languages; however, if it were the case, many people regarded as bilinguals would not be bilinguals. Most bilinguals have one language which is more dominant than the other (Grosjean, 1994). This statement is also proven by the participants of the present study as when they were asked which language is the dominant language; none stated "both languages", rather they preferred saying either language.

Back in time, there was a period when bilingual people were resembled schizophrenic individuals (Clarke, 1976). This was named as linguistic schizophrenia and the source of the belief came from the view that bilinguals have absurd identities since they are able to speak two languages. Adler (1977) informed people about being careful because bilingualism may pose a threat and results in psychological disorders. However, the perceptions of bilingualism have been remarkably changed in the last three decades. The findings of the present study support the new perceptions towards bilingualism. As a result of globalization, the borders are getting closer to one another in the world. Therefore, it is inevitable to mention the advantages of being able to speak two languages. This is how the majority of our participants thought, just like the participants of Fielding \& Harbon (2013). In their qualitative design, their participants also mentioned being lucky because they can communicate with other people, it was one of the most frequent codes that we came across. Yet still, feeling neutral is possible. Pavlenko (2007) stated that people living in multicultural environments and experiencing such environments every day might be less aware of linguistic and cultural facts. The multilingual participants of the present study showed consistency with this presume of the previous study. In the analysis of the findings, when participants were asked about their feelings when using both languages, it was seen that participants came up with feelings related to language use for their use of Turkish but the use of English was mostly described with proficiency-based feelings. Feeling natural or emotional might show that bilingual' experiences of naturalness and emotionality is more dominant in L1 and lower proficiency in L2 might be invoking the feeling of artificiality because of incompleteness of skills (Pavlenko, 2007). Description of language from the eyes of bilinguals showed that experi- ence with languages is a significant factor. Many bilinguals found English useful; the reason for this might be that most of the participants are LBs who arrived in English-speaking countries as young adults. English is the language of work. However, the results regarding description of Turkish were somehow unexpected. We expected feeling-based descriptions to be more frequent since the context of language learning shapes the way we think and behave (Koven, 2007). Our participants preferred describing Turkish with stereotypical adjectives. This finding suggests that the conceptions about language have something to do with speakers' belief about that language. The complexity and richness of the Turkish language are already a common belief in Turkish communities so the findings might be consistent with these beliefs.

\section{Bilingual Perception of Non-linguistic Features}

The tone of voice was the most frequent change that was mentioned by the participants. The reason might be consistent with SLA research studies. According to Patkowski (1990), the critical period for language learning may come to an end around the age of 15. After this period, acquiring native-like accent has been found almost impossible except for special cases. The overview concerning the issue is that learning a language at an early age enables speakers to be more capable of acquiring an accent (Flege and Fletcher, 1992; Patkowski, 1990). Seeing that participants are late starters of English language, raised awareness of non-nativeness might have taken their attention to their speech production since early bilinguals did not mention any change in their speech expect for speed. Participants' perception of speed can be attributed to their proficiency since EBs reported that they speak English faster while LBs reported vice versa.

Culture is such a comprehensive term that it is very easy to feel each part of it in every walk of life. The body language is one aspect shaped by culture. Contrary to what was expected, most of the bilinguals did not experience any change in their body language while switching languages. At least, this is what we were informed. Depending on participants' introspective explanations, our results contrasted with what Zhi-pen (2014) mentioned in his article: "A truly bilingual person switches his body language at the same time he switches language" (p.1033). Body movements associated with Turkish and facial movements associated with English can stand as a further implication as no previous study has included this issue. Still, reasoning about the findings would not be appropriate from a mono-cultural perspective. 


\section{Bilingual Perception of "Sense of Self"}

The perception of sense of self is dynamic within and from person to person. McWhorter (2014) claims that feeling different happens to LBs because of less proficiency in language. However, our results showed that some of the EBs reported feeling different. Feeling different is not related to age in which language starts to be learned nor to proficiency in that language (Dewaele, 2015). Dewaele and our findings showed consistency at this point. Yet, the majority of his participants reported a difference while less than half of our participants felt difference. This might have resulted from the fact that Dewaele's participants mostly consisted of multilinguals while we had more bilinguals in the present study, which can be another future implication for research. When the emerging codes are examined, we found out that "change within self" mostly includes the changes that can be categorized under extraversion. According to Wilson (2013), second language can be a mask for shy speakers and it is easy to feel difference when you wear it, thus what we believe is that the codes might have emerged due to possible shy participants. In the same direction, feeling calm can be a product of less proficient participants as it was stated by an LB and feeling kind can bear traces of culture. Still, certain conclusions cannot be drawn from the results seeing that some participants who share almost the same linguistic and demographic backgrounds gave opposite responses. These findings lead us to agree on Ozankska-Ponikwia (2013) claiming that feeling change in self is recognized and reported by only those who share certain personality traits. As personality traits and their relation with bilinguals' perceptions are not the focus of this study, such an argument calls for further research.

\section{Bilingual Perception of Biculturalism}

When people start to live in another culture, the self naturally changes to take part in the new environment (De leersnyder, Kim, \& Mesquita, 2015). An effort to go with the new environment is called as the process of acculturation. The present study shows that bilingualism and biculturalism are integrated as the majority of bilinguals reported themselves as biculturals. This finding was not unusual since language is the cornerstone to get into a brand new context. It is interesting that EBs reported their feelings as non-bicultural. Yet, we might reach to the fact that the perception of biculturalism is a dynamic phenomenon like the sense of self, as participants sharing the same linguistic and demographic backgrounds responded in different ways. Ryder, Alden and Paulhus (2000) claim that acculturation is two-sided in that heritage and host culture lie in different directions; while one culture is being approached with sympathy, the other still can be the culture of attachment. This dynamic nature is decided by the tendencies of people in terms of their beliefs. The accounts of participants about labelling themselves as biculturals are categorized under two main categories, depending on the relevant literature, as psychological and sociocultural adjustment (Schwartz, Unger, Zamboanga \& Szapocznik, 2010). We found more reasons addressing psychological adjustment in bilinguals' acculturation process. Same finding emerged when bilinguals came up with reasons about why the Turkish culture represents them. When representativeness of the British culture is asked, reasons addressing sociocultural adjustment came out. Although Benet-Martinez \& Ngujen (2013) argues that both domains have equal effects on cultural adjustment, the present study showed that biculturalism and perceptions of culture are mostly tied to psychological domains of acculturation. The reason why sociocultural adjustment is the code when participants were asked about changing as to cultural setting might be that cultural settings are constructed by society and embrace the culture within.

\section{Language Choice of Bilinguals}

To get an overview of how bilingual cognition works, three questions were addressed to participants. These questions were on a personal level, that is to say, they had nothing to do with interactional role of language. We seek to get a deeper understanding on what is hidden behind bilingual minds. The findings concerning language of inner speech have shown that language choice is not related to the age of onset as contrary to the research conducted by Larsen, Schrauf, Fromholt and Rubin (2002) since several EBs reported that the language of their inner voice is Turkish. The fact that the majority of participants, including EBs and LBs, stated that they use both languages leads us to think that context-based decisions are the underlying reason. It is the context or the situation deciding on the language choice of participants (Sansault, 2014).

In addition, the findings of biculturalism enable us to make a connection between inner speech and acculturation. Acculturation level is another factor affecting the language of inner speech (Halmer, 2017). Therefore, this might bring an explanation for LBs having their inner speech in English. Yet, participants sharing common backgrounds responded through two different ways for this question, as well. It is necessary to say that exact conclusions cannot be drawn since participants brought thousands of different variables with themselves to the present research.

Findings concerning mental calculation of bilinguals showed accordance with a previous research. The language of mental calculation is the language through which participants were taught to make calculation (Dewaele, 2007). However, some LBs reported using L2 for mental calculation. When demographic information of these participants were analysed, we found out that their occupation somehow requires making calculation, especially, on monetary issues. Thus, this new finding has shown us that the language of mental calculation can also include context-based decisions.

Additionally, findings regarding language choice of diary writing showed that most bilinguals tend to prefer which language they feel the ease since each has their unique explanations for preference, not a thorough conclusion comes out. Yet, it is seen that proficiency is something to do with it, while self-perceived proficiency has a bigger role in deciding. The choice of diary language is quite consistent with participants' feelings using two languages. It is related to participants' perception of languages, experiences with languages and self-perceived proficiency. Lastly, language 
options offered to participants while they were to fill in the questionnaire yield results in that most participants head for the one they learned earlier. Still, outliers exist. It is important to note that we might have been hit by "observer's paradox" which was mentioned by Labov (1972). Since we were to record their linguistic behaviors and the fact that they were aware might have resulted in a change in linguistic behaviors.

\section{CONCLUSION}

The results of the present study show that bilingualism is a wholly dynamic phenomenon. Even though bilinguals have linguistic and demographic information in common, they change in their nature. The data was analysed from five different perspectives, neither early bilinguals nor late bilinguals followed a straight way. In contrast, their route was with ups and downs. Self-perceived proficiency in languages, experiences with languages, context-based decisions, perceptions, beliefs and sense of self seemed to intricately act as remarkable parts in results. The perceptions of languages and bilingualism seem to depend on participants' proficiency and experience with languages. The use of body language was found to be related to culture and speech difference of bilinguals was linked to self-perceived proficiency. Feeling difference/change in self was found to be about sense of self while biculturalism and acculturation were dependent on the perceptions of bilinguals about themselves and cultures. Lastly, the language choice was found to be associated with self-perceived proficiency, speakers' perceptions of languages and context. According to the findings, aforementioned aims of the present study have been fulfilled and most of them showed accordance with the previous studies expect for the questions regarding each language as Turkish and English. We found out that bilinguals follow the same path with varying perceptions and beliefs about themselves and their environments. Thus, we assume that bilingual speakers are idiosyncratic and they display a unique profile (Grosjean, 1982; Pavlenko, 2007). Yet still, making assumptions about bilingualism is a challenging issue. For that reason, the results of this study do not aim to be generalizable; rather it is explanatory in terms of the fact that our focal point is the bilingual speakers of Turkish and English. The importance of this study lies in the fact that it investigates bilingual speakers of Turkish and English with a holistic point of view.

The limitations of this research are that the unequal number of early and late bilinguals and the small number of British participants might have affected the emerged codes in qualitative data analysis and results might be on the side of late bilinguals more. To be able to get more in-depth results, bilinguals could have been inquired by adopting a longitudinal design. Thus, further research in the field needs to be conducted by considering the limitations of the present study and adopting techniques from psychometrics due to the fact that data cannot be set on a concrete base. With the assistance of psychometrics, we believe that stronger findings about bilingual speakers of Turkish and English will come out.

\section{REFERENCES}

Adler, K. (1977) Collective and Individual Bilingualism: A Sociolinguistic Study. Hamburg: Helmut Buske Verlag.

Benet-Martinez, V., Lee, F., \& Leu, J. (2006). Biculturalism and cognitive complexity: Expertise in cultural representations. Journal of Cross-Cultural Psychology, 37, 386-407.

Berry, J. W., Phinney, J. S., Sam, D. L., \& Vedder, P. (2006). Immigration youth in cultural transition: Acculturation, identity, and adaptation across national contexts. Mahwah, NJ: Lawrence Erlbaum.

Bialystok, Ellen. 2005. Consequences of bilingualism for cognitive development. In Judith F. Kroll and Annette M. D. de Groot (eds.), Handbook of Bilingualism: Psycholinguistic Approaches. Oxford: Oxford University Press. 417-432.

Bialystok, E., Craik, F.I.M., \& Ryan, J. (2006). Executive control in a modified anti-saccade task: effects of aging and bilingualism. Journal of Experimental Psychology: Learning, Memory, and Cognition, 32, 1341-1354.

Centeno-Corte's, Beatriz and Antonio F. Jime'nez Jime'nez. 2004. Problem-solving tasks in a foreign language: the importance of the L1 in private verbal thinking. International Journal of Applied Linguistics 14(1), 7-35.

Clarke, M. (1976). Second language acquisition as a clash of consciousness. Language Learning 26(2), 377-90.

Cohen, Andrew D. 1994. The language used to perform cognitive operations during full immersion maths tasks. Language Testing 11(2), 171-195.

De Leersnyder, J., Kim, H., \& Mesquita, B. (2015). Feeling right is feeling good: Psychological well-being and emotional fit with culture in autonomy- versus relatedness-promoting situations. Frontiers in Psychology, 06.

Dewaele, J. (2007). Multilinguals' language choice for mental calculation. Intercultural Pragmatics, 4(3), 343-376.

Dewaele, J. (2015). Why do so many bi- and multilinguals feel different when switching Languages? International Journal of Multilingualism, 13(1), 92-105.

Dewaele, J.-M. and Pavlenko, A. (2001-2003) Web questionnaire Bilingualism and Emotions. University of London.

Dewaele, J.-M., \& Li Wei 2014. Intra- and inter-individual variation in self-reported code-switching patterns of adult multilinguals. International Journal of Multilingualism, 11,225-246.

Fielding, R., Harbon, L. (2013). Examining bilingual and bicultural identity in young students. Foreign Language Annals, 46(4), 527-544.

Flege, J. E., \& Fletcher, K. (1992). Talker and listener effects on the perception of degree of foreign accent. Journal of the Acoustical Society of America, 91, 370-389.

Grosjean, F. (1982). Life with Two Languages: An Introduction to Bilingualism. Cambridge, MA: Harvard University Press.

Grosjean, F. (1994). Individual bilingualism. In Asher, R. (ed.), The Encyclopedia of Language and Linguistics, pp. 1656-1660. Oxford: Pergamon Press.

Hoffman, E. (1989). Lost in Translation. A Life in a New Language. New York: Penguin Books. 
Hull, R. Vaid, J. (2007) Bilingual language lateralization: a meta-analytic tale of two hemispheres. Neuropsychologia, 45, 187-2008.

Koven M. 2007. Selves in Two Languages: Bilinguals'verbal enactments of identity in French and Portuguese. Amsterdam/Philadelphia: John Benjamins.

Labov, W. (1972). Sociolinguistic Patterns. Philadelphia: University of Pennsylvania Press.

Larsen, S.F., Schrauf, R.W., Fromholt, P., \& Rubin, D.C. (2002). Inner speech and bilingual autobiographical memory: A Polish-Danish cross-cultural study. Memory, $10,45-54$.

Lawshe, C. (1975). A Quantitative Approach to Content Validity. Personnel Psychology, 28(4), 563-575.

McWhorter J. H. 2014. The language Hoax. Oxford: Oxford University Press.

Nguyen, A.-M. D., \& Benet-Martínez, V. (2013). Biculturalism and adjustment: A meta-analysis. Journal of Cross-Cultural Psychology, 44, 122-159.

Oguibe, O. (1992). Culture grams. Provo, UT: Brigham Young University.

Ożańska-Ponikwia, K. 2012. What has personality and emotional intelligence to do with 'Feeling different' while using a foreign language? International Journal of Bilingual Education and Bilingualism, 15, 217-234.

Ożańska-Ponikwia, K. 2013. Emotions from a Bilingual Point of View: Personality and Emotional Intelligence in Relation to Perception and Expression of Emotions in the L1 and L2. Newcastle: Cambridge Scholars Publishing.
Patkowski, M. (1990). Age and accent in a second language: A reply to James Emil Flege. Applied Linguistics, 11,73-89.

Pavlenko, A. (2007). Bilingual minds. Clevedon: Multilingual Matters.

Rudmin, F. W. (2003). Critical history of the acculturation psychology of assimilation, separation, integration, and marginalization. Review of General Psychology, 7, 3-37.

Ryder, A. G., Alden, L. E., \& Paulhus, D. L. (2000). Is Acculturation Unidimensional or Bidimensional? A Headto-Head Comparison in the Prediction of Personality, Self-Identity, and Adjustment. Journal of Personality and Social Psychology, 79, 49-65.

Sansault, D. (2014). Représentations affectives dans le répertoire langagier de lycéens bilingues polono-français. Lingvaria, 9(17), 227-237.

Schrauf, R.W., \& Rubin, D.C. (2000). Internal lan- guages of retrieval: The bilingual encoding of memories for the personal past. Memory and Cognition, 28, 616-623.

Schwartz, S. J., Unger, J. B., Zamboanga, B. L., \& Szapocznik, J. (2010). Rethinking the concept of acculturation: Implications for theory and research. American Psychologist, 65, 237-251

Thomas, D. (2006). A General Inductive Approach for Analysing Qualitative Evaluation Data. American Journal of Evaluation, 27(2), 237-246.

Wilson, R.J. 2013. Another language is another soul. Language and Intercultural Communication.

Zhi-peng, R. (2014). Body Language in Different Cultures. US-Chine Foreign Language,(12)12, 1029-1033. 